\title{
Methanogenic and perchloroethylene-dechlorinating activity of anaerobic granular sludge
}

\author{
C. Kennes, M. C. Veiga, L. Bhatnagar
}

Applied Microbiology and Biotechnology, October 1998, Volume 50, Issue 4, pp 484488

DOI: $10.1007 / \mathrm{s} 002530051324$

\begin{abstract}
The biodegradation and toxicity of tetrachloroethylene $\left(\mathrm{C}_{2} \mathrm{Cl}_{4}\right)$ and trichloroethylene $\left(\mathrm{C}_{2} \mathrm{HCl}_{3}\right)$ were studied with different anaerobic enrichment cultures using the following electron donors: acetate, propionate, butyrate, methanol, formate and hydrogen. All of them sustained dechlorination except propionate, for which $\mathrm{C}_{2} \mathrm{Cl}_{4}$ biodegradation rates were not significant. The best results were obtained with butyrate. Hydrogen appeared to be a relevant electron donor for dechlorination with the present cultures. In the presence of specific inhibitors such as bromoethanesulphonate or molybdate, a slight inhibition of dechlorination was observed. According to dechlorination kinetics, Monod-type behaviour was observed up to $120 \mu \mathrm{M} \mathrm{C}_{2} \mathrm{Cl}_{4}$ or $200 \mu \mathrm{M} \mathrm{C}_{2} \mathrm{HCl}_{3}$ with $\mathrm{K} \mathrm{s}$ values around $7 \mu \mathrm{M}$ for both compounds. Dechlorination was partially inhibited at higher concentrations. In contrast, methanogens, or at least methane production, were more sensitive to the presence of chlorinated ethylenes and inhibition of methanogenesis was observed to different extents over all the $\mathrm{C}_{2} \mathrm{Cl}_{4} / \mathrm{C}_{2} \mathrm{HCl}_{3}$ concentration range tested, even at the lowest concentrations.
\end{abstract}




\section{Introduction}

Tetrachloroethylene or perchloroethylene $\left(\mathrm{C}_{2} \mathrm{Cl}_{4}\right)$ is widely used as a solvent and is listed as a priority pollutant in many industrialized countries. Owing to its presumed carcinogenic and mutagenic properties, investigations have been undertaken to check itsbiodegradability and removal from groundwater or contaminated environments in general.

So far, it has not been possible to obtain evidence of any $\mathrm{C} 2 \mathrm{Cl} 4$ biodegradation under aerobic conditions, although many reports have demonstrated the biodegradability of less-chlorinated ethylenes in the presence of oxygen by aerobic microorganisms (Alvarez-Cohen and McCarty 1991; Dobbins et al. 1995; Fogel et al. 1986; Nelson et al. 1987; Oldenhuis et al. 1991; Wilson and Wilson 1985). C2Cl4 is biodegradable by mixed cultures under anaerobic conditions (Bhatnagar et al. 1992; DiStefano et al. 1992; Smatlak et al. 1996; Tandol et al. 1994; Vogel and McCarty 1985; Wu et al. 1993). A few pure strains or highly enriched cultures able to degrade chlorinated ethylenes have also already been obtained, among which are Methanosarcina sp. (Fathepure and Boyd 1988) and other new genera or species (Fathepure et al. 1987; Holliger et al. 1993). A primary carbon and energy source is required to enable reductive dechlorination to take place. With mixed cultures or consortia, the choice of the primary carbon source plays a crucial role in the search of optimal dechlorination rates and pattern. The most suitable primary carbon source or electron donor will probably also depend on the origin of the inoculum. Acetate (Vogel and McCarty 1985), methanol (Fathepure and Boyd 1988; Freedman and Gossett 1989), lactate (Bagley and Gossett 1990), hydrogen (DiStefano et al. 1992; Smatlak et al. 1996) or mixtures thereof (Bhatnagar et al. 1992;Wuet al. 1993a, c) have been shown to support reductive dechlorination and to be suitable sources of electron donors.

In the present study, two cultures were selected from among several others for their ability to remove $\mathrm{C}_{2} \mathrm{Cl}_{4}$ anaerobically. Enrichments were undertaken in the presence of different electron donors including acetate, propionate, butyrate, methanol, formate and hydrogen, the best results being obtained with butyrate according to biodegradation rates. The influence of specificc inhibitors on $\mathrm{C}_{2} \mathrm{Cl}_{4}$ removal was checked to evaluate the roleof specific microbial groups. Biodegradation kinetics and toxicity of $\mathrm{C}_{2} \mathrm{Cl}_{4}$ and $\mathrm{C}_{2} \mathrm{HCl}_{3}$ were determined both for dechlorinators and for methanogens.

\section{Materials and methods}

\section{Inocula and media}

Culture A originating from pentachlorophenol-degrading methanogenic granules (Kennes et al. 1996; Wu et al. 1993b) was enriched with a medium containing C2Cl4 and a mixture of acetate, propionate, butyrate and methanol. Culture B was a mixture of different sludges from industrial wastewater treatment plants and a culture from a fixedfilm reactor degrading a complex mixture of chlorinated compounds (Modesto Filho et al. 1991). The culture medium (50 ml) (Kenealy and Zeikus 1981) used in batch assays was introduced into 158-ml serum vials with Teflon-coated septa and aluminium caps. It contained a vitamin solution (Wolin et al. 1963) and Na2S 9H2O as reducing agent. The medium was buffered with a $\mathrm{K}_{2} \mathrm{HPO}_{4} / \mathrm{KH}_{2} \mathrm{PO}_{4}$ mixture and the $\mathrm{pH}$ was adjusted to 7.0 \pm 7.2. Chloroethylenes were added after the vials had been autoclaved for $20 \mathrm{~min}$ at $120{ }^{\circ} \mathrm{C}$. Initial chloroethylene concentrations were determined by GC analysis by sampling the vials 15 min after adding the chlorinated compounds in order to allow 
equilibrium to be reached between the di

analysed during the course of the experiments, a vial was sacrificed, after methane measurement, for determination of chloroethylene concentrations and primary substrate consumption. All experiments were undertaken in duplicate.

\section{Chemicals}

Chlorinated compounds were obtained from Janssen Chimica (Beerse, Belgium), Fluka (Buchs, Switzerland) or Aldrich Chemical Company (Milwaukee, USA). Bromoethanesulphonate (BES) was purchased from Sigma (St. Louis, USA).

\section{Analytical methods}

Methane and fatty acids were determined by gas chromatography as described elsewhere (Kennes et al. 1996; Soto et al. 1997). Formate was analysed on a model 600 HPLC from Waters with a BioRad $87 \mathrm{H}$ column after acidification of the sample. Chlorinatedcompounds were determined by GC on a Hewlett-Packard, model 5890A gas chromatograph. The samples were either extracted with iso-octane or heated in order to transfer all the contaminants to the gas phase for analysis of headspace samples (Wu et al. 1993c). Other parameters, such as volatile suspended solids, were determined according to Standard Methods (APHA-AWWA-WPCF 1985).

\section{Results}

Influence of the source of electron donor on removal of chlorinated ethylenes and toxicity of chlorinated ethylenes According to data reported in the literature, the rate and extent of $\mathrm{C}_{2} \mathrm{Cl}_{4}$ biodegradation observed with anaerobic cultures are often di erent from one study to another. In the present case, the behaviour of two different cultures was checked. These cultures were selected from others after having shown their ability to dechlorinate $\mathrm{C}_{2} \mathrm{Cl}_{4}$ anaerobically. In order to establish the role of several electron donors in $\mathrm{C}_{2} \mathrm{Cl}_{4}$ dechlorination, the following substrates were tested with both cultures: acetate, propionate, butyrate, methanol, formate and a $\mathrm{H}_{2} / \mathrm{CO}_{2}(80: 20)$ mixture. Two control bottles were used: (i) a non-inoculated medium, (ii) a bottle autoclaved with medium and cells in exponential growth phase prior to $\mathrm{C}_{2} \mathrm{Cl}_{4}$ addition. The synthetic medium described above for biodegradation experiments was initially prepared with tap water as well as with distilled water, leading to very similar removal rates. All further experiments were then undertaken with distilled water to ensure fully reproducible working conditions.

In order to adapt the cells to $\mathrm{C}_{2} \mathrm{Cl}_{4}$ and to reach a high biomass concentration in the bottles, the cultures were first grown on a volatile fatty acid (acetate, propionate, butyrate) plus methanol (1 mM each) mixture, in the presence of $5 \mathrm{lM} \mathrm{C}_{2} \mathrm{Cl}_{4}$. After complete exhaustion of the substrates, the bottles were ${ }^{-}$ushed with nitrogen or $\mathrm{H}_{2} / \mathrm{CO}_{2}$ and the desired electron donors and $\mathrm{C}_{2} \mathrm{Cl}_{4}$ were supplied to the medium to check biodegradation of the chlorinated ethylenes.

The experiments were undertaken with the following initial $\mathrm{C}_{2} \mathrm{Cl}_{4}$ concentrations (lM): 7, 40, 80, 120 and 160. These concentrations represent approximate values and varied slightly from one vial to another but always with less than 5\% deviation according to GC analysis. Both cultures were able to degrade $\mathrm{C}_{2} \mathrm{Cl}_{4}$ with each of the electron donors tested, except propionate. The rate and extent of $\mathrm{C}_{2} \mathrm{Cl}_{4}$ removal were, however, different, as appears in Table 1 . Several successive $\mathrm{C}_{2} \mathrm{Cl}_{4}$ spiking steps were applied for each of the different primary carbon sources. $\mathrm{C}_{2} \mathrm{Cl}_{4}$ dechlorination rates increased after 
each step. The maximal specific $\mathrm{C}_{2} \mathrm{Cl}_{4}$ dechlorination rates reported in Table 1 were obtained from the fourth spiking step, since the removal rates were very similar to those obtained on the third spiking. No $\mathrm{C}_{2} \mathrm{Cl}_{4}$ dechlorination was observed in non-inoculated bottles.

To check the influence of a heat treatment on $\mathrm{C}_{2} \mathrm{Cl}_{4}$ dechlorination in the presence of a $\mathrm{H}_{2} / \mathrm{CO}_{2}$ mixture, bottles inoculated with the enrichment cultures were autoclaved for 20 min at $120{ }^{\circ} \mathrm{C}$. From the experimental results it could be concluded that the dechlorination capacity was lost after such treatment since basically no $\mathrm{C}_{2} \mathrm{Cl}_{4}$ biodegradation was found after 1 week. The removal rates were of the same order of magnitude with both cultures. $\mathrm{C}_{2} \mathrm{Cl}_{4}$ removal rates and complete dechlorination were, however, faster in the presence of butyrate. With the latter substrate, when yeast extract was added (0.1\%), $\mathrm{C}_{2} \mathrm{Cl}_{4}$ dechlorination rates increased by a factor of approximately 1.5. The trend shown in Table 1 for $\mathrm{C}_{2} \mathrm{Cl}_{4}$ was, as a general rule, also observed for the less-chlorinated compounds, which were removed more slowly in the presence of acetate. Figure 1 shows a typical biodegradation pattern for culture B grown on butyrate. As appears in that figure, the less-chlorinated compounds were removed more slowly. Both the cis and trans $\mathrm{C}_{2} \mathrm{H}_{2} \mathrm{Cl}_{2}$ isomers were formed during $\mathrm{C}_{2} \mathrm{Cl}_{4}$ biodegradation studies, at similar rates and concentrations. Peaks corresponding to trace levels of $1,1-\mathrm{C}_{2} \mathrm{Cl}_{2} \mathrm{H}_{2}$ were also detected by GC analysis.

Table 1 Maximal C2Cl4 dechlorination rates obtained with two di $\square$ erent anaerobic cultures using di $\square$ erent primary carbon sources. \pm minor or slow removal, VSS volatile suspended solids, ND not done.

\begin{tabular}{lll}
\hline Electron donor & \multicolumn{2}{l}{$\begin{array}{l}\text { Maximal specific } \mathrm{C}_{2} \mathrm{Cl}_{4} \text { dechlorination rates } \\
\left(\mu \mathrm{mol} \mathrm{h} \mathrm{hgVSS}^{-1}\right)\end{array}$} \\
\cline { 2 - 3 } & Culture A & Culture B \\
\hline Acetate & 52.7 & 92.2 \\
Propionate & - & - \\
Butyrate & 311.3 & 262.0 \\
Methanol & 185 & 242.0 \\
Formate & 196.7 & $\mathrm{ND}$ \\
$\mathrm{H}_{2} / \mathrm{CO}_{2}$ & 202 & 229.9 \\
\hline
\end{tabular}

In batch experiments undertaken with butyrate as primary carbon source, zero-order kinetics appeared best to represent the C2Cl4 biodegradation pattern for the $40 \pm 120 \mathrm{lM}$ $\mathrm{C}_{2} \mathrm{Cl}_{4}$ concentration range. However, from the lower biodegradation rate observed at 7 $\mathrm{IM}$ it could be concluded that Monod kinetics does apply, with a Monod constant for $\mathrm{C}_{2} \mathrm{Cl}_{4}$ slightly below $7 \mathrm{lM}$ (Fig. 2). Only at higher initial $\mathrm{C}_{2} \mathrm{Cl}_{4}$ concentrations (160 lM) was inhibition of $\mathrm{C}_{2} \mathrm{Cl}_{4}$ removal observed. However, inhibition of methane production was observed at all $\mathrm{C}_{2} \mathrm{Cl}_{4}$ concentrations tested (from $7 \mathrm{lM}$ to $160 \mathrm{lM}$ ). Typical methane production experiments are shown in Fig. 3a for the different $\mathrm{C}_{2} \mathrm{Cl}_{4}$ concentrations. 


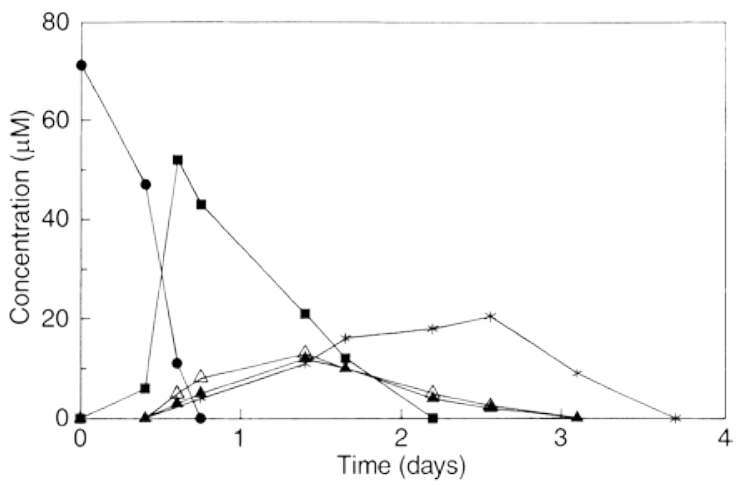

Fig. 1 Typical $\mathrm{C}_{2} \mathrm{Cl}_{4}$ dechlorination profile obtained with culture $\mathrm{B}$ and butyrate as source of electron donor. $-\mathrm{C}_{2} \mathrm{Cl}_{4},-\mathrm{C}_{2} \mathrm{HCl}_{3}, \Delta$ cis- $\mathrm{C}_{2} \mathrm{H}_{2} \mathrm{Cl}_{2}, \boldsymbol{\Delta}$ trans- $\mathrm{C}_{2} \mathrm{H}_{2} \mathrm{Cl}_{2}$, * vinylchloride

Toxicity and biodegradation rates were also determined with trichloroethylene and butyrate, for initial $\mathrm{C}_{2} \mathrm{HCl}_{3}$ concentrations of 9, 20, 40, 120, 200 and $300 \mathrm{lM}$. Here again, a zero-order biodegradation kinetics pattern was observed in the $40 \pm 200 \mathrm{lM}$ $\mathrm{C} 2 \mathrm{HCl} 3$ concentration range and inhibition was observed at $300 \mathrm{lM}$. At the lowest concentrations tested, Monod kinetics was observed with a Monod constant around 7 IM. As was observed with $\mathrm{C}_{2} \mathrm{Cl}_{4}, \mathrm{C}_{2} \mathrm{HCl}_{3}$ is also inhibitory to methane production and inhibition was already appreciable at $40 \mathrm{lM} \mathrm{C}_{2} \mathrm{HCl}_{3}$ (Fig. 3b). On the other hand, $\mathrm{C}_{2} \mathrm{HCl}_{3}$ removal rates remained basically the same in the concentration range $9 \pm 200 \mathrm{lM}$ $\mathrm{C}_{2} \mathrm{HCl}_{3}$ and equal to $180 \mathrm{lmol} \mathrm{h}^{-1} \mathrm{mg}$ volatile suspended solids ${ }^{-1}$.

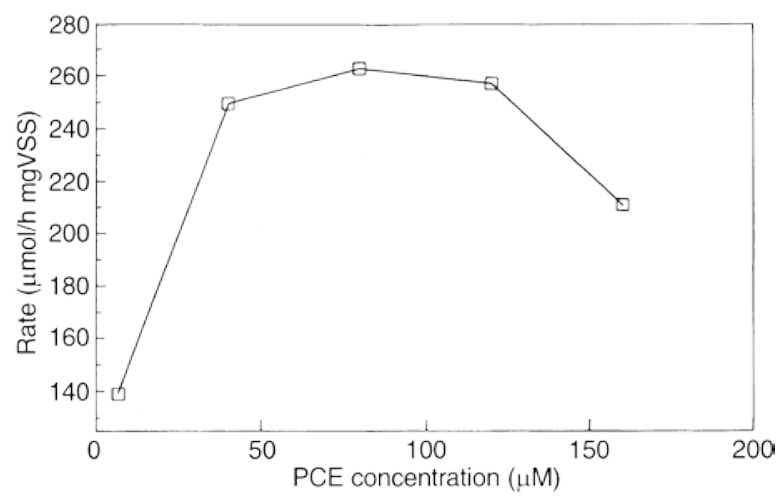

Fig. 2 Specific $\mathrm{C}_{2} \mathrm{Cl}_{4}$ removal rates versus initial $\mathrm{C}_{2} \mathrm{Cl}_{4}$ concentrations with butyrate as source of electron donor

\section{Effect of specific inhibitors}

Butyrate enrichments of culture $\mathrm{B}$ were grown batchwise in the presence of $\mathrm{C}_{2} \mathrm{Cl}_{4}$ and the following specific inhibitors: $\mathrm{BES}(5 \mathrm{mM}), \mathrm{Na}_{2} \mathrm{MoO}_{4}(5 \mathrm{mM})$ and hydrogen. In the case of bottles used to study inhibition of sulphate-reducing bacteria, sulphate was added to the medium in the form of $\mathrm{Na}_{2} \mathrm{SO}_{4}(3 \mathrm{mM})$. Bottles with sulphate were also used to demonstrate that the presence of sulphate did not significantly inhibit or enhance $\mathrm{C} 2 \mathrm{Cl} 4$ biodegradation.

BES and molybdate, which specifically inhibited methanogenesis or sulphate reduction, did slightly inhibit $\mathrm{C}_{2} \mathrm{Cl}_{4}$ biodegradation. In the presence of $\mathrm{BES}$ or molybdate a $16 \%$ and an $8 \%$ inhibition were respectively observed according to $\mathrm{C}_{2} \mathrm{Cl}_{4}$ biodegradation rates. 
Later on the $\mathrm{C}_{2} \mathrm{Cl}_{4}$ enrichment culture was grown in the presence of both butyrate and hydrogen (1.5 atm overpressure). In such experiments dechlorination started without any lag phase and complete $\mathrm{C}_{2} \mathrm{Cl}_{4}$ disappearence was observed while the butyrate concentration remained basically unchanged during $\mathrm{C}_{2} \mathrm{Cl}_{4}$ removal.
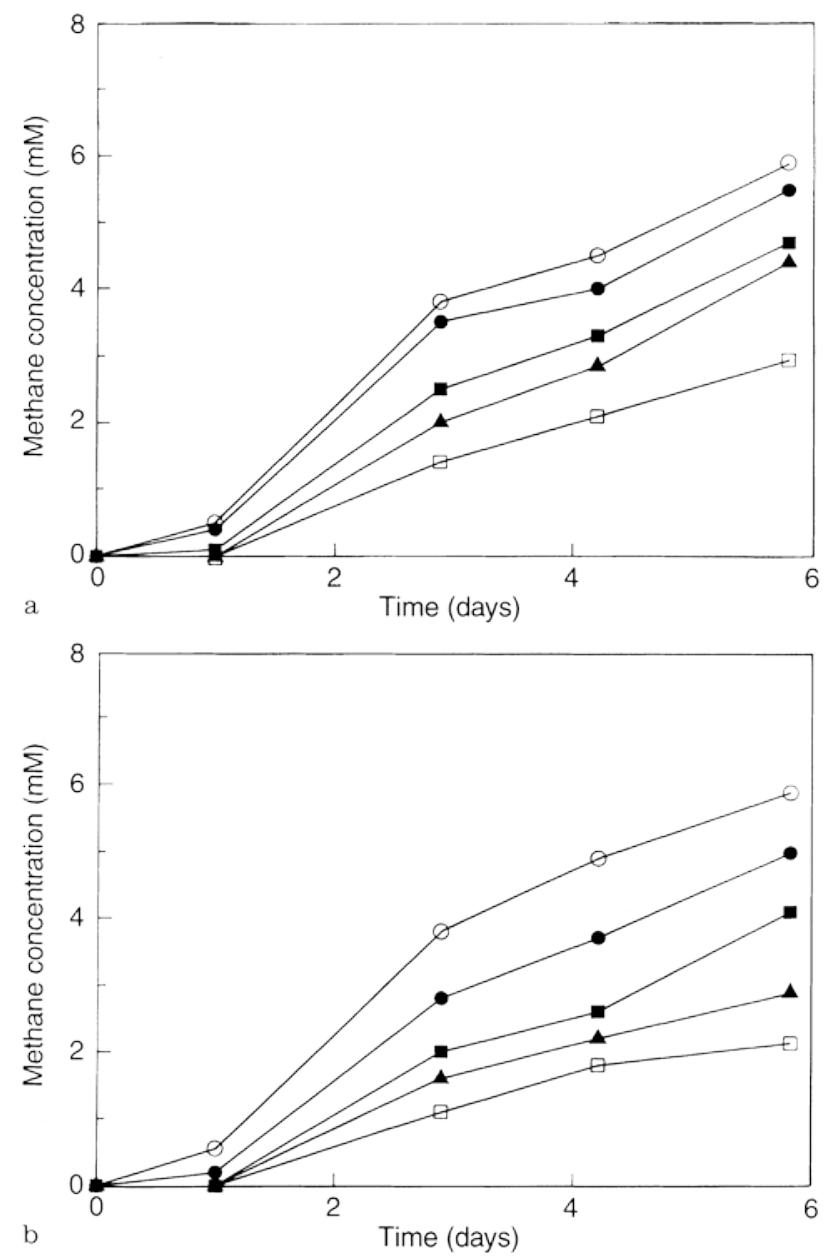

Fig. 3a Cumulative methane production as a function of time with culture $\mathrm{B}$ and butyrate at initial $\mathrm{C}_{2} \mathrm{Cl}_{4}$ concentrations of $(\mu \mathrm{M}) 0(\mathrm{O}), 7(\bullet), 40(\boldsymbol{\bullet}), 80(\boldsymbol{\Delta}), 160(\square)$. b Cumulative methane production as a function of time with culture $\mathrm{B}$ and butyrate at different $\mathrm{C}_{2} \mathrm{HCl}_{3}$ concentrations of $(\mu \mathrm{M}) 0(\mathbf{O}), 40(\bullet), 120(\boldsymbol{\square}), 200(\mathbf{\Delta}), 300(\square)$

\section{Enumeration and enrichment studies}

After several transfers in aqueous medium with $\mathrm{C}_{2} \mathrm{Cl}_{4}$, samples of the enriched cultures grown on butyrate or on hydrogen/carbon dioxide were serially diluted and poured on lates under strict anaerobic conditions, using either butyrate or a $\mathrm{H}^{2} / \mathrm{CO}^{2}$ mixture as substrates. $\mathrm{C}_{2} \mathrm{Cl}_{4}$ was also added on the plates. Different morphotypes were found although a regular short rod was highly dominant in both cases. Aliquots of the dilution series were transferred under sterile conditions to fresh medium containing either $\mathrm{H}^{2}$ / $\mathrm{CO}^{2}$ alone or a mixture of $\mathrm{H}_{2} / \mathrm{CO}_{2}$ and $\mathrm{C}_{2} \mathrm{Cl}_{4}$, to evaluate the ratio of methanogenic bacteria and $\mathrm{C} 2 \mathrm{Cl} 4$ dechlorinators in the medium. Each dilution was prepared in triplicate to give a ratio of approximately 107 methanogens to 106 dechlorinators. 


\section{Discussion}

Under strict anaerobic conditions, the dechlorination of halogenated toxic compounds is dependant on the nature of the electron donors utilized. The inoculum source is another important factor. Both parameters were studied and the present data are compared to other recently published results. As already mentioned, depending on the microbial community and culture conditions used, different primary carbon sources or sources of electron donors may be suitable for $\mathrm{C}_{2} \mathrm{Cl}_{4}$ dechlorination (Bagley and Gossett 1990; DiStefano et al. 1992; Fathepure and Boyd 1988; Smatlak et al. 1996; Vogel and McCarty 1985; Wu et al. 1993), either in the presence or in the absence of sulphate (Freedman and Gossett 1989). The results reported so far suggest that, in some cases, dechlorinators may represent new species and/or genera (Holliger et al. 1993; DeWeerd et al. 1990), although at least some methanogens and sulphate-reducing bacteria also seem to be able to biodegrade $\mathrm{C}_{2} \mathrm{Cl}_{4}$ and other chloroaliphatic compounds (Fathepure and Boyd 1988; Egli et al. 1987).

In the present case, butyrate was the most suitable electron donor to sustain the dechlorination of chloroethylenes (Table 1). $\mathrm{C}_{2} \mathrm{Cl}_{4}$ removal was also possible without any butyrate consumption in the presence of hydrogen. The fact that $\mathrm{C}_{2} \mathrm{Cl}_{4}$ dechlorination was not inhibited when both butyrate and hydrogen were used as the source of electron donors suggests that hydrogen rather than butyrate is important in dechlorination. The exact dechlorination mechanisms have not been elucidated so far.

Enhancement of biodegradation in the presence of yeast extract indicates the key role of non-identified micro-elements or other compounds in $\mathrm{C}_{2} \mathrm{Cl}_{4}$ removal. The complete inhibition of the dechlorinating activity when autoclaved cells were used, together with the effect of specific inhibitors, indicate that the dechlorination process is due to the metabolic activity of living cells of specific microbial groups. When single primary substrates were used, methanol, hydrogen and formate were less effcient than butyrate. The slowest biodegradation rates were observed with acetate and almost no $\mathrm{C}_{2} \mathrm{Cl}_{4}$ removal was found with propionate. These data suggest the important role of hydrogen for $\mathrm{C}_{2} \mathrm{Cl}_{4}$ dechlorination with the present cultures, which is in agreement with recently reported results (DiStefano et al. 1992; Smatlak et al. 1996). The cultures were enriched in liquid medium, although no pure colonies could be isolated in the presence of $\mathrm{C}_{2} \mathrm{Cl}_{4}$ on plates.

Limited inhibition of dechlorination was observed with specific inhibitors of methanogenesis or sulphate reduction, suggesting that methanogens or sulphate reducers only play a minor role \pm if any \pm in dechlorination, or otherwise that inhibitors of methanogenesis and sulphate reduction do also show influence on dechlorination mechanisms. $\mathrm{C}_{2} \mathrm{Cl}_{4}$ as well as $\mathrm{C}_{2} \mathrm{HCl}_{3}$ was inhibitory to methanogenic activity even at low concentrations. In contrast, inhibition of dechlorination activity was not detected at such $\mathrm{C}_{2} \mathrm{Cl}_{4}$ and $\mathrm{C}_{2} \mathrm{HCl}_{3}$ concentrations, which again seems to indicate that de chlorinating microorganisms are probably not methanogens. Since both methanogens and dechlorinators use hydrogen as electron donor, their competition for hydrogen might explain the inhibition of methanogenesis in the presence of chlorinated ethylenes, as was also recently suggested by Ballapragada and coworkers (Ballapragada et al. 1997). At relatively low $\mathrm{C}_{2} \mathrm{Cl}_{4}$ and $\mathrm{C}_{2} \mathrm{HCl}_{3}$ concentrations, Monod kinetics are observed, with Ks values close to $7 \mathrm{lM}$ for both compounds. This has to be taken into account for bioremediation studies since removal rates will significantly decrease below such a concentration. These data were, by the way, obtained during spiking experiments, after adaptation of the cultures to chloroethylenes, from which it can be 
concluded that no (further) natural improvement of kinetic parameters might be expected.

Reductive dechlorination of $\mathrm{C}_{2} \mathrm{Cl}_{4}$ and $\mathrm{C}_{2} \mathrm{HCl}_{3}$ in the presence of the various primary carbon sources yielded, in all cases, both the cis and the trans isomers of dichloroethylene as well as trace levels of $1,1-\mathrm{C}_{2} \mathrm{Cl}_{2} \mathrm{H}_{2}$, contrary to other reports where only one isomer was detected (Bagley and Gossett 1990). In all cases $\mathrm{C}_{2} \mathrm{Cl}_{4}$ and $\mathrm{C}_{2} \mathrm{HCl}_{3}$ were completely dechlorinated. Degradation of dichloroethylenes to non-chlorinated compounds appeared to be much slower than $\mathrm{C}_{2} \mathrm{Cl} 4$ or $\mathrm{C}_{2} \mathrm{HCl}_{3}$ removal and suggests the potential for using integrated anaerobic/aerobic systems for a complete decontamination of $\mathrm{C}_{2} \mathrm{Cl}_{4}$ using the anaerobic stage for the initial fast $\mathrm{C}_{2} \mathrm{Cl}_{4}$ dechlorination and the aerobic stage for further complete biodegradation of less chlorinated ethylenes to nontoxic compounds. It is indeed well known that less chlorinated ethylenes can be degraded completely and rapidly by aerobes (Alvarez-Cohen and McCarty 1991; Dobbins et al. 1995; Fogel et al. 1986; Nelson et al. 1987; Oldenhuis et al. 1991; Wilson and Wilson 1985).

\section{Acknowledgements}

Special thanks are due to Drs. J.G. Zeikus and W.-M. Wu for their collaboration and suggestions. The Michigan Biotechnology Institute is acknowledged for allowing publication of some of the results obtained at that Institute.

\section{References}

Alvarez-Cohen L, McCarty PL (1991) E Tards redutcesincity, aeration, supply on trichloroethylene transformation by a mixed methanogenic culture. Appl Environ Microbiol 57: 228-235

APHA-AWWA-WPCF (American Public Health Association -American Water Works Association - Water Pollution Control Federation) (1985) Standard methods for the examination of water and wastewater, 16th edn. American Public Health Association, Washington, DC

Bagley DM, Gossett JM (1990) Tetrachloroethane transformation to trichloroethane and cis-1,2-dichloroethane by sulfate-reducing enrichment cultures. Appl Environ Microbiol 56: 2511-2516

Ballapragada BS, Stensel D, Puhakka JA, Ferguson JF (1997) E reductive dechlorination of chlorinated ethenes. Environ Sci Technol 31: 1728-1734

Bhatnagar L, Kennes C, Wu W-M, Zeikus JG (1992) Dechlorination of tetrachloroethylene by methanogenic granules. In: 92nd Annual Meeting of the American Society for Microbiology, ASM (ed.) New Orleans, La, 27士-0 May

DeWeerd KA, Mandelco L, Tanner RS, Woese CR, Suflita JM (1990) Desulfomonile tiedjei gen. nov. and sp. nov., a novel anaerobic, dehalogenating, sulfate-reducing bacterium. Arch Microbiol 154: 23-30

DiStefano TD, Gossett JM, Zinder SH (1992) Hydrogen as an electron donor for dechlorination of tetrachloroethene by an anaerobic mixed culture. Appl Environ Microbiol 58: 3622-3629 
Dobbins DC, Peltola J, Kustritz JM, Chresand TJ, Preston JC (1995) Pilot-scale demonstration of a two-stage methanotrophic bioreactor for biodegradation of trichloroethylene in ground-water. J Air Waste Manage Assoc 45: 12-19

Egli T, Scholtz CR, Cook AM, Leisinger T (1987) Anaerobic dechlorination of tetrachloromethane and 1,2-dichloroethane to degradable products by pure cultures of Desulfobacterium sp. and Methanobacterium sp. FEMS Microbiol Lett 43: 257-261

Fathepure BZ, Boyd SA (1988) Reductive dechlorination of perchloroethylene and the role of methanogens. FEMS Microbiol Lett 49: 149-156

Fathepure BZ, Nengu JP, Boyd SA (1987) Anaerobic bacteria that dechlorinate perchloroethane. Appl Environ Microbiol 53: 2671-2674

Fogel MM, Taddeo AR, Fogel S (1986) Biodegradation of chlorinated ethenes by a methane-utilizing mixed culture. Appl Environ Microbiol 51: 720-724

Freedman DL, Gossett JM (1989) Biological reductive dechlorination of tetrachloroethylene and trichloroethylene to ethylene under methanogenic conditions. Appl Environ Microbiol 55: 2144-2151

Holliger C, Schraa G, Stams AJM, Zehnder AJB (1993) A highly purified enrichment culture couples the reductive dechlorination of tetrachloroethane to growth. Appl Environ Microbiol 59: 2991-2997

Kenealy W, Zeikus JG (1981) Influence of corrinoid antagonists on methanogen metabolism J Bacteriol 146: 133-140

Kennes C, Wu W-M, Bhatnagar L, Zeikus JG (1996) Anaerobic dechlorination and mineralization of pentachlorophenol and 2,4,6-trichlorophenol by methanogenic pentachlorophenol-degrading granules. Appl Microbiol Biotechnol 44: 801806

Modesto Filho P, Amerlynck P, Nyns EJ, Naveau HP (1991) Acclimatization of a methanogenic consortium to polychlorinated compounds in a fixed film stationary bed reactor. In: Proceedings of the 6th International Symposium on Anaerobic Digestion, ABES/IAWPCR (ed.), Sao-Paulo, Brazil, 12-16 May

Nelson MJK, Montgomery SO, Maha

(1980)RBiBdieghaddtPdH of trichloroethylene and involvement of an anaerobic biodegradative pathway. Appl Environ Microbiol 53: 949-954

Oldenhuis R, Oedzes JY, Waarde JJ van der, Janssen DB (1991) Kinetics of chlorinated hydrocarbon degradation by Methylosinus trichosporium OB3b and toxicity of trichloroethylene. Appl Environ Microbiol 57: 7-14

Smatlak CR, Gosset JM, Zinder SH (1996) Comparative kinetics of hydrogen utilization for reductive dechlorination of tetrachloroethene and methanogenesis in an anaerobic enrichment culture. Environ Sci Technol 30: 2850-2858

Soto M, Ligero P, Vega A de, Veiga MC, BlaÂ zquez R (1997) Sludge granulation in UASB digesters treating low strength wastewaters at mesophilic and psychrophilic temperatures. Environ Technol 18: 1133-1141

Tandol V, DiStefano TD, Bowser PA, Gosset JM, Zinder SH (1994) Reductive dehalogenation of chlorinated ethenes and halogenated ethenes by a high-rate anaerobic enrichment culture. Environ Sci Technol 28: 973-979 
Vogel TM, McCarty PL (1985) Biotransformation of tetrachloroethylene to trichloroethylene, dichloroethylene and carbon dioxide under methanogenic conditions. Appl Environ Microbiol 49: 1080-1083

Wilson JT, Wilson BH (1985) Biotransformation of trichloroethylene in soil. Appl Environ Microbiol 49: 242-243

Wolin EA, Wolin MRJ, Wolfe RS (1963) Formation of methane by bacterial extracts. J Biol Chem 238: 2882-2886

Wu W-M, Kennes C, Nye J, Hickey RF, Bhatnagar L (1993a) Reductive dechlorination of tetrachloroethylene using anaerobic granules. In: Biotechnology applications in hazardous waste treatment. American Chemical Society, Wash, DC, pp 132-136

Wu W-M, Bhatnagar L, Zeikus JG (1993b) Performance of anaerobic granules for degradation of pentachlorophenol. Appl Environ Microbiol 59: 389-397

Wu W-M, Nye J, Hickey RF, Bhatnagar L (1993c) Anaerobic granules developed for reductive dechlorination of chlorophenols and chlorinated ethylene. In: Proceedings of the $48^{\text {th }}$ Purdue Industrial Waste Conference, Purdue University (ed.),

West Lafayette, Purdue, Ind, USA, 10-12 May. pp. 483-493 